\title{
MODELING THE EVOLUTION OF A CRACK IN A PRESTRESSED CONCRETE STRUCTURE
}

\author{
E.LEFEBVRE $^{* \dagger}$, S.MICHEL-PONNELLE ${ }^{\dagger}$ E.LORENTZ $^{\dagger}$ AND F.FEYEL $^{\dagger \dagger}$ \\ Ecole des Mines ParisTech, Centre des Matériaux \\ Paris, France \\ e-mail : eric-lefebvre@mines-paristech.fr \\ ${ }^{\dagger}$ IMSIA, UMR 9219 CNRS/EDF/CEA/ENSTA, \\ Paris, France \\ e-mail : sylvie-michel.ponnelle@edf.fr, eric.lorentz@edf.fr \\ ${ }^{\dagger+}$ Safran Tech, Safran SA, \\ Saclay, France \\ e-mail : frederic.feyel@safran.fr
}

Key words: Prestressed concrete structure, Fracture, Steel-Concrete debonding

\begin{abstract}
This work focuses on following an existing crack in a pre-stressed concrete structure without describing the early stages of damage. This leads to an estimation of the overall leakage of the structure. A "global model" is proposed that represents most phenomena interacting with the behaviour of an existing crack. The model is built from a real cracking pattern. The existing cracks are taken into account through a cohesive zone model; steel reinforcements and pre-stressing tendons are modelled by means of homogenized membrane models; the debonding steel-concrete is represented by another specific cohesive zone model. The constitutive law used for modelling the concrete takes into account basic creep (through a rheological model distinguishing the deviatoric part and the spherical part), shrinkage and drying creep.
\end{abstract}

\section{Introduction}

EDF- the major French electricity Company-manages 73 nuclear reactors. For some of them, the third protective barrier consists in a concrete double-walled containment building. The key point of such predictions consists in describing the behaviour of potential cracks. However, the size of the structure coupled with the important proportion of reinforcements along with the nonlinear constitutive behaviour of concrete are challenging issues.

The diameter of the prestressing cables is 10 times smaller than the thickness of the wall and its density is significant. A 3D model of the cables is the straightforward answer in this case but it leads to prohibitive simulation times so that alternative methods need to be employed. An usual solution
$[1,2]$ consists in modelling the cables with truss elements. Unfortunately, such modelling results in spurious stress concentrations in the surrounding volume [3] and it generally assumes a perfect steelconcrete bond. Therefore we prefer to use a membrane element, for which the behaviour is obtained by homogenization $[3,4,5]$. Numerically, this type of modelling - less common in the literature - does not generate stress concentration.

Pre-stressed structures also require to take into account delayed deformation phenomena of concrete such as creep. In the long term, the delayed strains cause a significant pre-stress drop. They are usually modelled by means of constitutive laws based either on rheological intuitions or on homogenization methods [6].

Regarding the fracture process of concrete, damage models may simulate crack initiation and propagation while taking into account the complex 
behaviour of concrete [7]. However, the question of the resulting mesh-dependency (ill-posed problems) needs to be addressed through nonlocal constitutive laws, see [8] for instance, which results in time- computations. Moreover several physical phenomena responsible for crack initiation during the construction of a building are difficult to represent using such models. As a consequence, it is assumed that the location and the crack paths are a priori known.

We propose in this paper a method to predict the crack behaviour (extension, opening, ...). The cracks and the steel-concrete debonding are described using cohesive zone models, while steel reinforcements and pre-stressing tendons are modelled by homogenized membrane models. The paper is organized as follows: In section 2, the formulation of a mixed interface finite element is presented. Several tests validate its use for reinforced concrete structures in section 3 . The simulation of a part of the containment building with an initial pre-crack state is performed in section 4.

\section{Description of the modelling}

In order to describe the long-term behaviour of cracks, cohesive zone models are used to simulate simultaneously the cracks and the steel-concrete debonding process. Despite the restrictive hypothesis of a postulated crack path, both phenomena can cohabitate without major numerical problems.

\subsection{Description of the bulk cracking in the concrete}

\subsubsection{A mixed interface finite element for crack}

In our case, the crack path $\Gamma$ is considered given a priori and going straight through the wall. Among the different approaches to model cracks in concrete, cohesive zone models are selected as one of the easiest approach. The mixed interface finite element introduced in [9] is chosen because it can deal with intrinsic cohesive laws unlike more standard cohesive elements that are restricted to extrinsic laws. A short description of the model is presented in this section.

In their approach to Cohesive Fracture Mechanics, Francfort and Marigo [10] describe the state of a structure $\Omega$ through the displacement field $\mathbf{u}$ which may admit discBntipuities $\delta \overline{\bar{C}} \overline{\bar{c}}, \mathbf{u}_{26}$ across surfaces $\Gamma(\mathbf{u})$. The energy depends explicitly on both $\mathbf{u}$ and $\delta$.

$$
E(\mathbf{u}, \delta)=\int_{\Omega \backslash \Gamma} \Phi(\varepsilon(\mathbf{u})) d \Omega-W_{e x t}(\mathbf{u})+\int_{\Gamma} \Pi(\delta) d \Gamma
$$

where $\varepsilon$ is the strain tensor, $\mathbf{u}$ the displacement field, $\boldsymbol{\delta}$ the discontinuities of the displacement field, $\Phi$ the strain energy density and $\Pi$ the cohesive surface energy density.

The solution of the problem corresponds a minimum energy condition. The constraint $\delta=[\mathbf{u}]$ is ensured by dualisation, leading to the following (augmented) Lagrangian with $\lambda$ being the Lagrange multiplier field:

$$
\begin{aligned}
L_{r}(\mathbf{u}, \delta, \lambda)=E(\mathbf{u}, \delta)+ & \int_{\Gamma} \lambda \cdot([\mathbf{u}]-\delta) d \Gamma \\
& +\int_{\Gamma} \frac{r}{2}([\mathbf{u}]-\delta)^{2} d \Gamma
\end{aligned}
$$

where $r$ is a penalty parameter introduced to gain some coercivity. The corresponding first-order optimality conditions read:

$$
\begin{aligned}
& \forall \delta \delta \int_{\Gamma}[\mathbf{t}-\hat{\boldsymbol{\lambda}}-\boldsymbol{r}(\llbracket \mathbf{u} \rrbracket-\delta)] \cdot \delta \delta \mathrm{d} \Gamma=0 \quad \text { with } t \in \partial \Pi(\boldsymbol{\delta}) \\
& \forall \delta \mathbf{u} \int_{Q, \Gamma} \boldsymbol{\sigma}: \boldsymbol{\varepsilon}(\delta \mathbf{u}) \mathrm{d} \Omega+\int_{\Gamma}[\hat{\lambda}+\mathrm{r}([\mathbf{u}]-\delta)] \cdot[\delta \mathbf{u}] \mathrm{d} \Gamma=W_{\text {ext }}(\delta \mathbf{u}) \\
& \text { with } \sigma=\frac{\partial \Phi}{\partial \varepsilon}(\varepsilon) \\
& \forall \delta \boldsymbol{\lambda} \int_{\Gamma}(\llbracket \mathbf{u} \rrbracket-\delta) \cdot \delta \hat{\lambda} \mathrm{d} \Gamma=0
\end{aligned}
$$

The crack path $\Gamma$ can be discretized with degenerated prisms or bricks (or quadrangles in 2D). In the mixed interface finite element, the displacement $\mathbf{u}$ is a quadratic interpolation with P2-continuous polynomials, the Lagrange multiplier field $\mathbf{t}$ with $\mathrm{P} 1$-continuous polynomials and the local auxiliary field $\delta$ with P1discontinuous polynomials. This interpolation allows us to respect the Ladyzhenskaya-BabuskaBreezi conditions.

\subsubsection{Cohesive law for the cracking of concrete}

Several traction-separation laws are available in the literature in order to model the 
cracking process of concrete: bi-linear [11], exponential [12] and polynomial [13]. These three laws are very similar in terms of initial slope and cohesive length, which are the most important features for the cohesive law [14]. While the most common law employed is the bilinear one (Eq 5.), an exponential law is here preferred since only two material parameters (the tensile strength $\sigma_{c}$ and the fracture energy $G_{f}$ ) need to be identified, whereas four of them are needed for a bilinear law (Fig.1). In the table 1 , the length of cohesive $\delta_{\mathrm{c}}$ is equal to $3.2 \mathrm{G}_{\mathrm{f}} / \sigma_{c}$.

Table 1: cohesive law for concrete

\begin{tabular}{c|c} 
Exponential law & $\sigma(\delta)=\sigma_{c} \exp \left(-\delta / \delta_{c}\right)$ \\
\hline Bi-linear law & $\left\{\begin{array}{c}\sigma(\delta)=\sigma_{c}-3 \frac{\sigma_{c}}{\delta_{c}} \delta, \delta<\delta_{c} \\
\sigma(\delta)=\frac{3}{7} \sigma_{c}-\frac{3 \sigma_{c}}{7 \delta_{c}} \delta\end{array}\right.$ \\
\hline Polynomial law & $\sigma(\delta)=\sigma_{c}\left(1-\delta / \delta_{c}\right)^{2}$
\end{tabular}

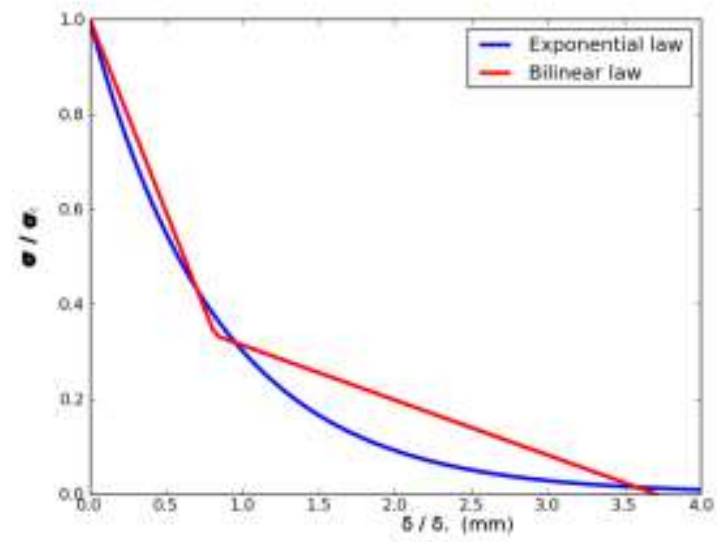

Figure 1 Bilinear and exponential cohesive laws

\subsection{Modelling of the steel in the concrete}

Here, both rebars and tendons are modeled using membrane elements [5]. Such choice ensures a well-posed mathematical problem unlike truss elements, and simultaneously avoid high stress concentrations in the vicitiny the beam elements and mesh dependency [20]. These elements can be employed simultaneous with cohesive element to order to describe the degradation of the steelconcrete bond, as properly explained in [5].
2.2.1 Steel-Concrete debonding model

Since the work of Goto[14] and Eljgehausen and co [15] , the phenomenology of the steelconcrete debonding process is reasonably understood. Shear cracks are initiated by the ribs. Beyond a threshold, damage is initiated in the compressed concrete ahead of the ribs (Fig 2).

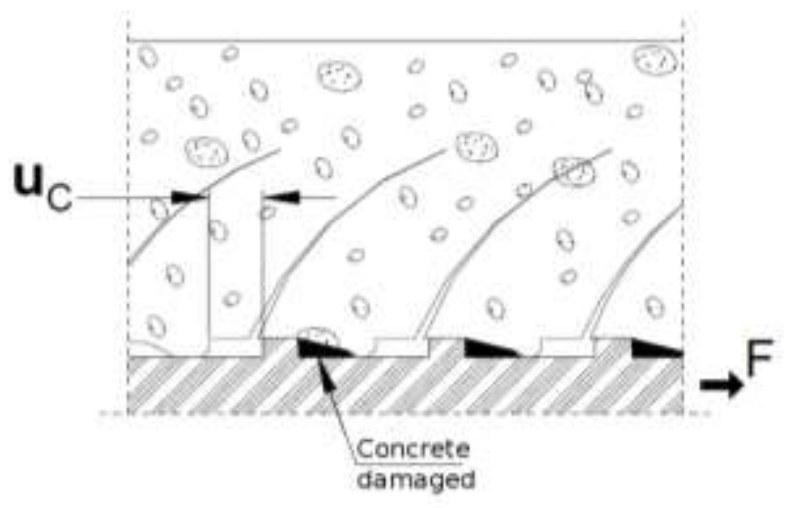

Figure 2 Degradation of the steel-concrete interface

In order to simulate this phenomenon, the debonding law (fig 3. and eq 2.) proposed by M. David [5] is employed which results in similar strength-shift curves obtained by Eligehausen [9]. The model defines the shear stress $\tau$ as a function of the maximum concrete-steel debonding. The parameters of the law are specified in Table 1, where $\tau_{\mathrm{m}}$ and $\mathrm{a}_{\mathrm{m}}$ control the peak position while the parameters $\alpha$ and $\beta$ influence the post and prepeak responses.

$$
\tau(a)=\tau_{m}(\alpha+\beta)^{\alpha+\beta} \frac{\left(a / a_{m}\right)^{\alpha}}{\left(\alpha a / a_{m}+\beta\right)^{\alpha+\beta}}
$$

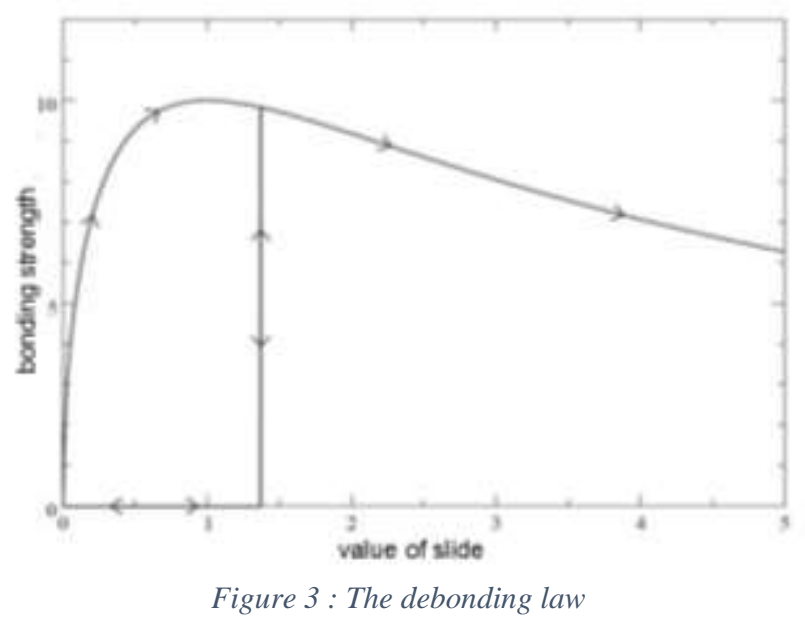


Table $2:$ Parameters of the debonding law

\begin{tabular}{l|l|l|l} 
Parameter & Field & Unit & Definition \\
\hline$a_{m}$ & $R$ & $\mathrm{~m}$ & $\begin{array}{l}\text { Displacement } \\
\text { at the peak }\end{array}$ \\
\hline$\tau_{m}$ & $\mathrm{R}$ & $\mathrm{Pa}$ & $\begin{array}{l}\text { Max shear } \\
\text { stress }\end{array}$ \\
\hline$\alpha$ & ] $0,1[$ & - & Initial growth \\
\hline$\beta$ & $\mathrm{R}$ & - & $\begin{array}{l}\text { Final decay } \\
\text { law }\end{array}$
\end{tabular}

\subsubsection{A mixed interface finite element for debonding steel-concrete}

The mixed interface finite element is used in order to represent the debonding law as suggested in [5]. This choice provides an efficient cohabitation with the modelling of cracks since both of them rely on a cohesive description.

We define for a cable oriented along $\mathbf{e}_{2} \mathrm{u}_{\mathrm{f}}$ the displacement of the fibre and the debonding $\xi$ such as:

$$
\mathbf{u}^{\zeta}=\mathbf{u}+\zeta \mathbf{e}_{2}
$$

The behaviour of the interface is characterized by a unique state variable, denoted a, which is the maximum slip debonding over its whole history and irreversible (eq. 8). The mechanical energy in the steel-concrete interface is defined in (9).

$$
\begin{gathered}
\left\{\begin{array}{l}
\xi \mid<a \\
\dot{a} \geqslant 0
\end{array}\right. \\
\Upsilon(a)=\frac{\pi d}{e} \int_{0}^{\infty} \tau(\widetilde{a}) d(\tilde{a})
\end{gathered}
$$

The formulation of the mechanical potential is defined as the sum of the mechanical energy present in the concrete, the membrane and the steel-concrete interface:

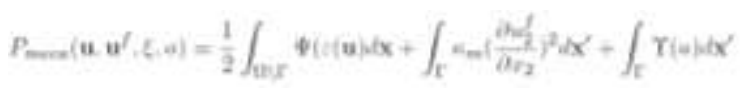

where $\kappa_{\mathrm{m}}$ is a stiffness coefficient and $\Upsilon$ the energy of the interface. In order to solve the problem, an approach similar to the one proposed in Section 2.1 is employed.. Again, a dualisation of the constraint is used by introducing a Lagrange multiplier $\zeta$ and a penalty parameter $\mathrm{r}$ :

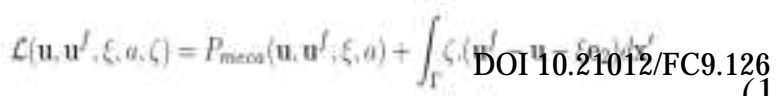

$$
+\frac{k}{2} \int_{\Gamma} \mid u^{\prime}-u-\left\{\left.e_{2}\right|^{2} d x^{\prime}\right.
$$

The minimization of the mechanical potential (10) under the constraint (7) and (8) is equivalent to finding the saddle-point of the Lagrangian (11).

The interface can be discretised with degenerated element. For the mixed interface finite element, the displacements $\mathbf{u}$ and $\mathbf{u}^{\mathrm{f}}$ are interpolated using P2-continuous polynomials, whereas the Lagrange multiplier field $\zeta$ uses P1continuous polynomials and the local auxiliary field $\xi$ employs P1-discontinuous polynomials.

\section{Validation of the different models}

In this part, the mixed interface finite element is employed in order to simulate the debonding process along a reinforcement and to predict the fracture of a RC structure and a prestressed concrete structure.

\subsection{Debonding simulation along reinforcement}

The first experiment is a three-point bending test performed on prismatic samples of $70 \times 70 \times 280$ $\mathrm{mm}^{3}$ size reinforced with a $6 \mathrm{~mm}$ steel bar in the middle of the samples (Fig. 4) [17]. A crack is initiated in the middle of the sample, and intercepts the steel bar. A displacement sensor measures the opening of the notch (Fig. 4).

The main interest of this experimental campaign, is that the length of damage along the bar, called debonding length, has been quantified by ensuring the carbonation method of the sample after cracking (Fig. 5). A curve with the length of damage along the bar for three value of crack openings (Fig 6) is given, that could be compared to simulation.

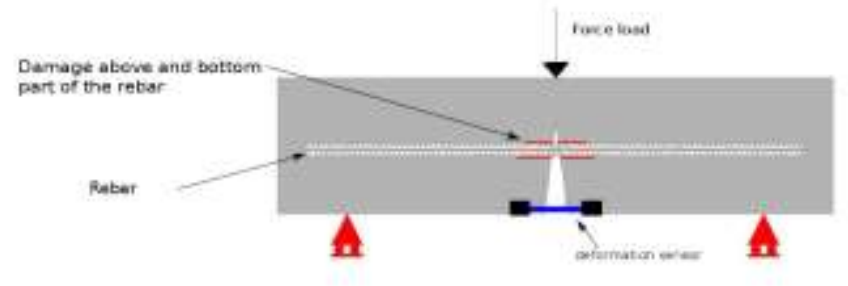

Figure 4: The three points bending beam 


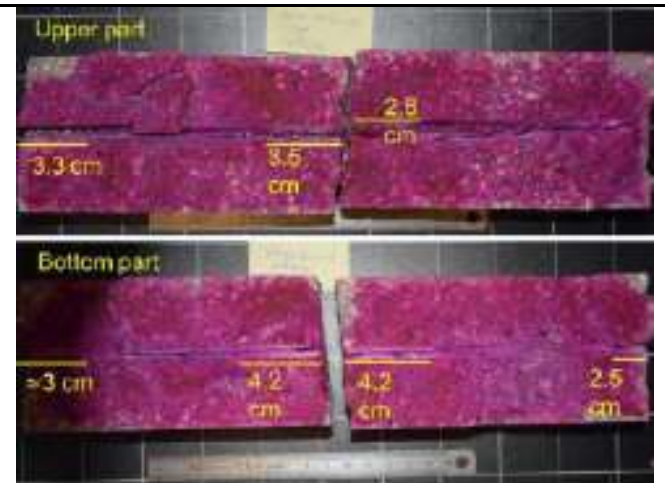

Figure 5 : Fracture surface of the beam [17]

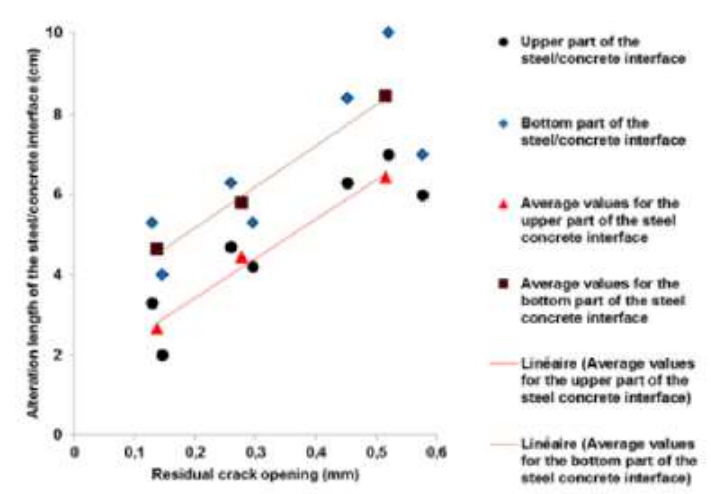

Figure 6: The length of damage for three values of the opening crack [17]

The beam is meshed using 20000 elements. Since the crack initiates in the middle of the sample, a plane of cohesive elements is inserted in the centre of the specimen. The rebar is modelled using a plane of membrane elements (Fig. 7). The decohesion between steel and concrete is also introduced thanks to cohesive elements.

The constitutive laws are the following :

- Elasticity for the concrete (3D elements) and the steel (membrane);

- the exponential cohesive law (eq.4) for the vertical crack ;

- the debonding steel/concrete described in section 2.2.1 for the interface between the concrete and the steel.

The material parameters of the concrete are detailed in the table 2 .

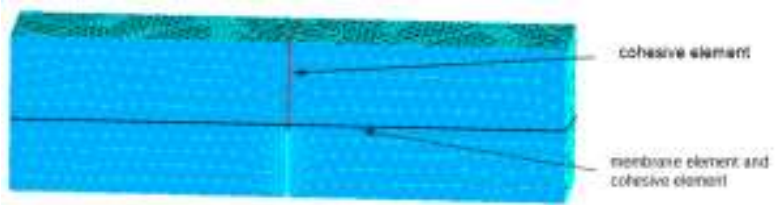

Figure 7: Mesh of the notched beam
Tableau 1: Parameters of the notched beam

\begin{tabular}{c|c|r|c}
$\mathrm{E}$ & $v$ & $\sigma_{\mathrm{t}}$ DOf $10.21 \mathrm{G} 2 / \mathrm{FC} 9.126$ \\
\hline $30 \mathrm{GPa}$ & 0.2 & $3 \mathrm{MPa}$ & $100 \mathrm{~N} / \mathrm{m}$
\end{tabular}

In the experimental test, two debonding lengths are measured: one for the upper part of the cable and one for the bottom part (Fig. 4-5-6). However in the modelling a single value for the length of debonding is obtained because the damage is represented by a single layer of cohesive element. Figure 8 represents the sliding of the steel as a function of the distance to the beam's centre. The debonding length is defined as the distance between the crack and the first element with a near-zero slip. The sliding between the membrane and the concrete decreases as a function of the distance to the crack. The dispersion of the results is caused by the unstructured mesh. As shown in the figure 5, the sliding between the steel and the concrete is symmetric with respect to the crack plane.

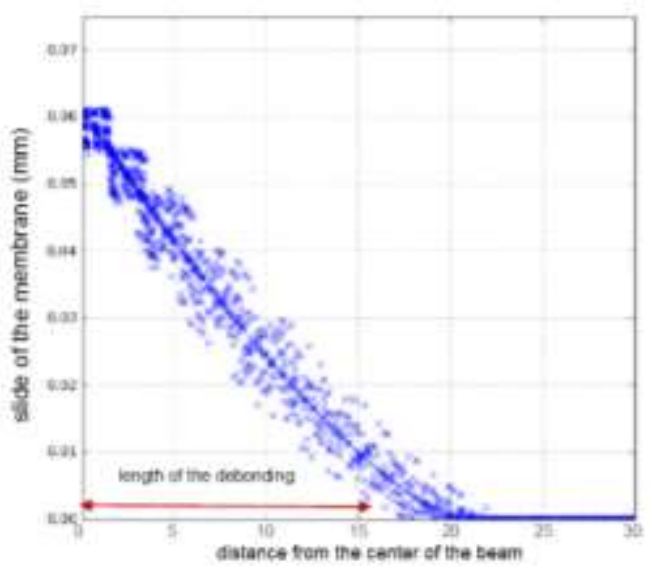

Figure 8: slide of the membrane vs distance from the centre of the beam

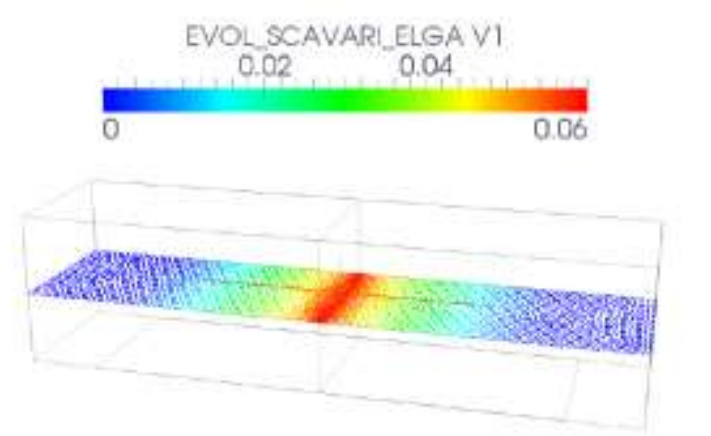

Figure 9 : slide of the membrane for an opening of $0.5 \mathrm{~mm}$ 
Figure 10 shows the debonding length as a function of the crack opening for several sets of parameters of the steel-concrete interface law (see table 3). The experimental results correspond to the dashed-line. The debonding length obtained from the modelling is close to the experimental measures. The steel-concrete debonding can be represented by cohesive elements with a debonding law. A sensitivity analysis highlights the importance of the peak stress position compared to the other two parameters $\alpha$ and $\beta$ in the debonding law.

Tableau 2 Parameters for the debonding law

\begin{tabular}{c|c|c|c} 
CZM_LAB_MIX & $\mathrm{a}(\mathrm{mm})$ & $\alpha$ & $\beta$ \\
\hline P1 & 1 & 0.5 & 2 \\
\hline P2 & 1 & 0.1 & 8 \\
\hline P3 & 0.6 & 0.5 & 2
\end{tabular}

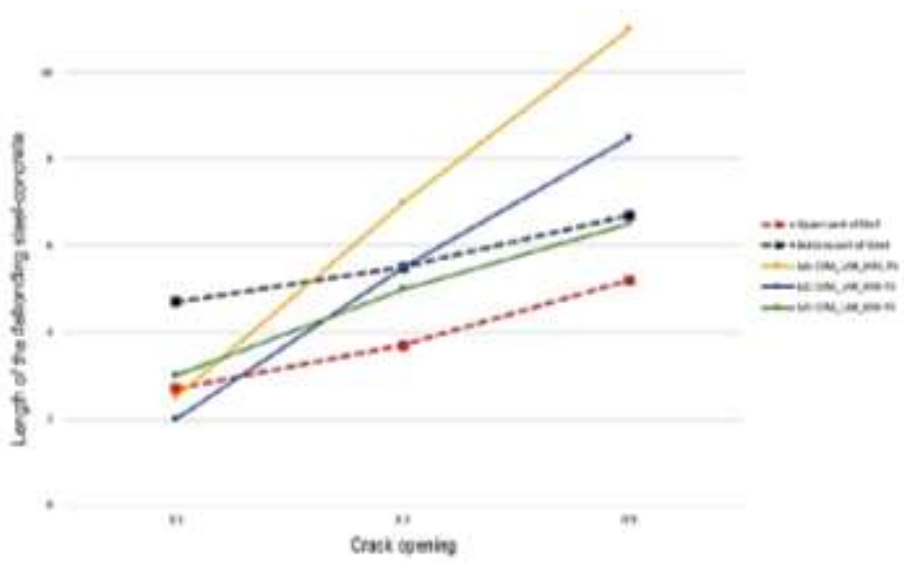

Figure 10: Length of debonding vs crack opening

The debonding length is correctly predicted for different crack opening values. As a consequence, it validates the debonding law and the assembly of the interface elements for concrete cracking and for the steel-concrete debonding.

\subsection{Prediction global and local response of $\mathrm{RC}$ Structure}

In this section, behaviour of a reinforced concrete beam is simulated and compared to experimental and numerical results in terms of force-displacement curves and number of cracks and their widths. The beam considered is the MECA beam [18]. The beam's dimensions are 5.4 $\mathrm{m} \times 0.5 \mathrm{~m} \times 0.2 \mathrm{~m}$ and the reinforcement are shown in figure 11. The beam is loading to 3 point bending.

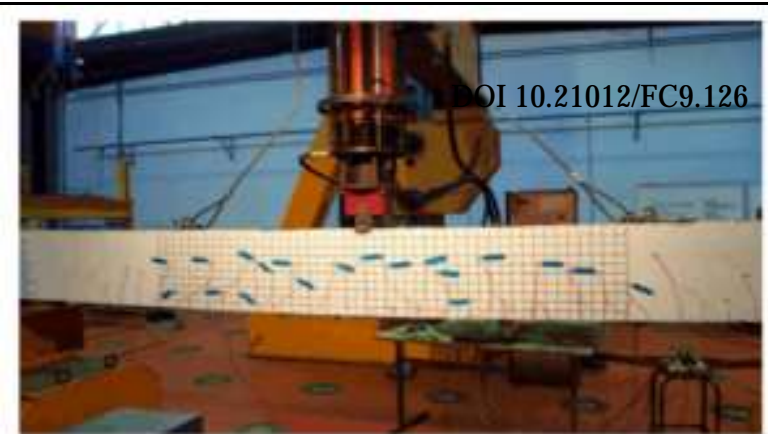

Figure 11 : Experimental test of the beam in the three-point bending

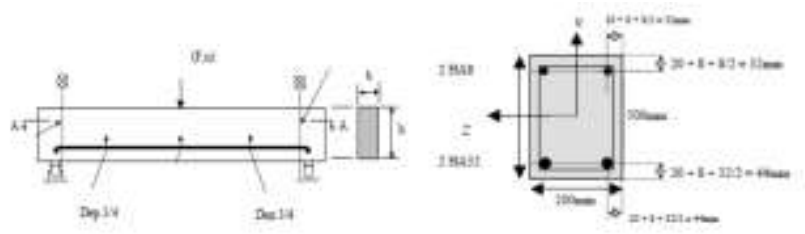

Figure 12 Schema of the reinforcing steel in the beam

The reinforcements are represented by two horizontal planes of membrane elements. The steel-concrete debonding is modelled using mixed interface elements with the debonding law presented in section 2.2. In order to verify the space discretization's convergence of the model, different meshes are created using 6, 9, 24 and 49 equidistant cohesive surfaces.

The boundary conditions of the beam are depicted in Figure 13. The material parameters are detailed in table 3.

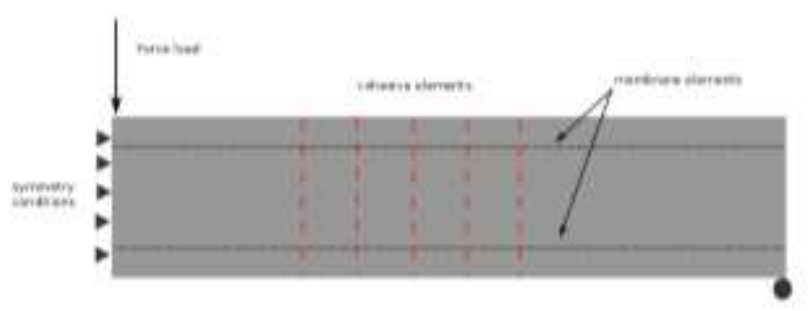

Figure 13: Boundary conditions

Table 3 : Concrete parameters

\begin{tabular}{c|c|c|c}
$\mathrm{E}$ & $v$ & $\sigma_{\mathrm{t}}$ & $\mathrm{G}_{\mathrm{f}}$ \\
\hline $37.2 \mathrm{GPa}$ & 0.2 & $3.68 \mathrm{MPa}$ & $100 \mathrm{~N} / \mathrm{m}$
\end{tabular}

Figure 14 shows the deformed configuration of the beam using 24 cohesive cracks for three levels of loading. The first open cracks are concentrated in the central part of the beam, as in the experimental test, whereas at the end of the test, the open cracks are uniformly distributed on the three quarters of the beam. In figure 15, the loading versus the vertical displacement of the beam is shown for the different meshes and 
compared to the experimental results. An increase in the number of cohesive surfaces decreases the beam's resistance to flexion and reduces the differences between the numerical and the experimental curves. Beyond 24 cohesive surfaces, the behaviour of the beam does not evolve and the number of open cracks remains constant. For 24 and 49 cohesive cracks, the number of open crack does not exceed 16 (Table 4) and the average opening displacement converges to $230 \mu \mathrm{m}$. In conclusion, if the number of cohesive planes is sufficiently large enough, the behaviour of the beam does not evolve anymore and is close to the experimental results.
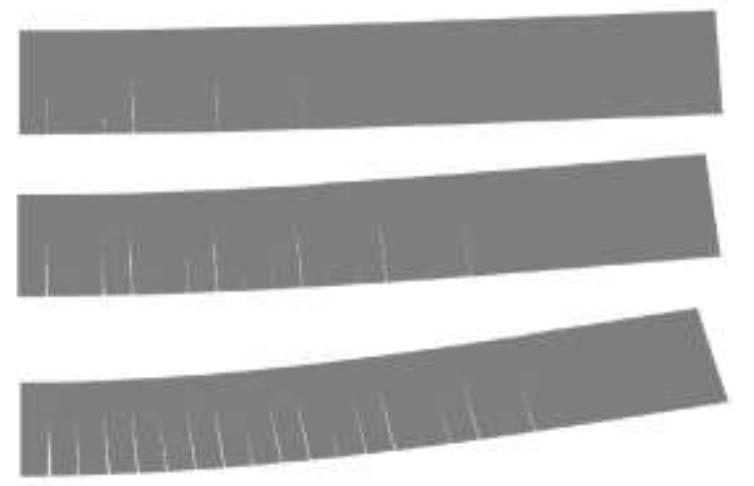

Figure 14 : Representation of the flexion of the beam with 24 cracks for 3 levels of loading

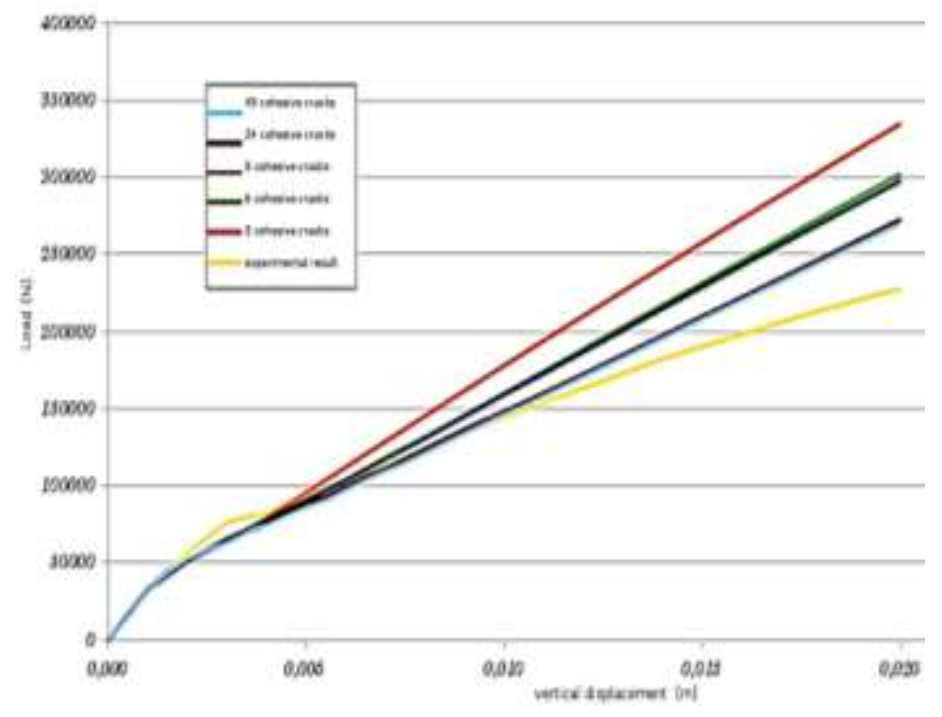

Figure 15 : Comparison of the beam behaviour for different number of cracks
Table 4 Results of the numerical test

\begin{tabular}{|c|c|c|c|}
\hline $\begin{array}{l}\text { Number of } \\
\text { cohesive } \\
\text { cracks }\end{array}$ & $\begin{array}{l}\text { Number of } \\
\text { opened } \\
\text { cracks }\end{array}$ & $\begin{array}{l}\text { OpDoing0.2 } \\
\text { maximum } \\
(\mu \mathrm{m})\end{array}$ & $\begin{array}{l}\text { 2Afreages } \\
\text { opening } \\
(\mu \mathrm{m})\end{array}$ \\
\hline 49 & 16 & 420 & 230 \\
\hline 24 & 16 & 520 & 234 \\
\hline
\end{tabular}

However, a space discretization with a minimum number of elements between each cohesive surface must be respected in order to have an accuracy on stress fields. An increase in the number of potential cracks involves the number of finite elements in the mesh. A trade-off must be chosen in order to obtain a sufficiently well-represented beam behaviour while limiting simulation time.

\subsection{Description of a prestressed concrete structure and evolution of opening cracks}

\subsubsection{Description of the test [18]}

In 2005, EDF R\&D and the MPA Karlsruhe decided to cooperate in project «PACE1450» [18], which's goal is to investigate the behaviour of a curved specimen representative of a 1450 MWe nuclear power plant containment under accidental loading conditions. The specimen has realistic dimensions and therefore can be loaded very similarly to a closed ring under internal pressure. It is designed as a cut-out of the cylindrical part of a pre-stressed nuclear reactor containment (see Fig.16).

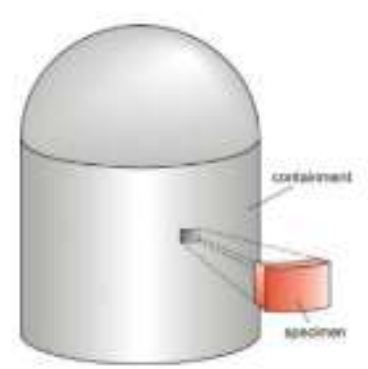

Figure 16 The specimen is cut out of the cylindrical part of the containment [18]

The dimension of the specimen is $2.4 \mathrm{~m} \times 1.8 \mathrm{~m}$ $\mathrm{x} 1.2 \mathrm{~m}$. It is pre-stressed using four horizontal cables consisting each of 37 strands. A vertical prestressing cable is inserted in the specimen but no load is applied. The inner and outer reinforcing grids have a diameter of $20 \mathrm{~mm}$, with a spacing of $200 \mathrm{~mm}$ as shown in Fig 17. 


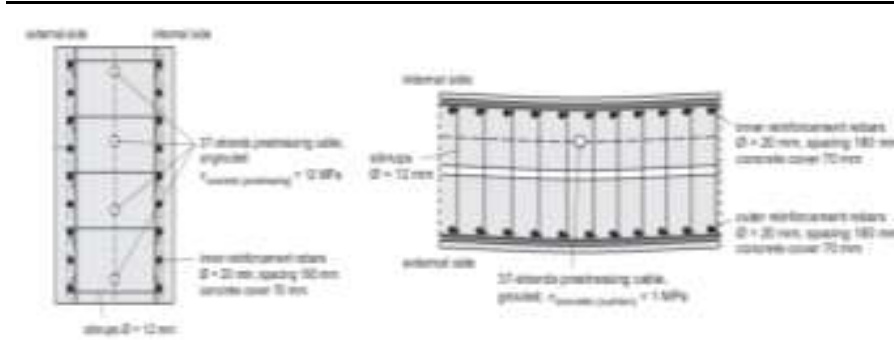

Figure 17 : Sections of the specimen as part of the containment

The externally applied tensile force corresponds to the ring tensile force coming from the internal pressure within the reactor containment under inspection or accidental conditions. Each test of the specimen is named "RUN". The membrane force that would occur in a closed ring under internal pressure is enforced by hydraulic jacks pushing apart the so called "ears" which are transverse beams made of steel. They are connected to the specimen by reinforcement bars and load the specimen with the tensile force.

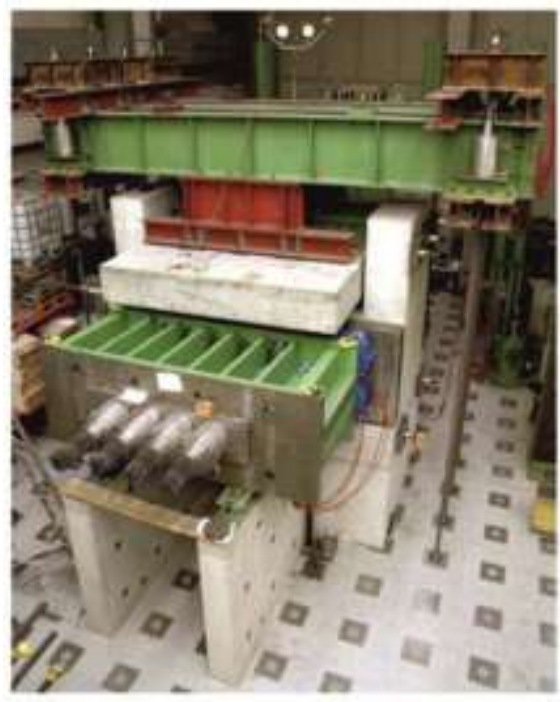

Figure 18:PACE 1450

For practical reasons, in order to speed up creep and its effects on the post-tensioning system, the pre-stressing forces have been gradually decreased in time (see Table 5). At the RUN 4, the specimen has been subjected to a pressure of 6 bar up to the creation of the cracks. After the RUN 4, many sensors have been added on the cracks in order to measure the opening of the cracks during the tests, in particular during the RUN 6, 17 months later.
Table 5 : Test Program

\begin{tabular}{|c|c|c|c|c|c|}
\hline & RUN1 & RUN2 & RCINB.2 & 10RX/AC49. & 2RUN5-6 \\
\hline Prestress. & $100 \%$ & $80 \%$ & $60 \%$ & $60 \%$ & $60 \%$ \\
\hline Pressure & $5.3 \mathrm{bar}$ & 5.3 bar & 5.3 bar & 6 bar & 6 bar \\
\hline Time & $\begin{array}{c}2.5 \\
\text { months }\end{array}$ & $\begin{array}{c}3.5 \\
\text { months }\end{array}$ & $\begin{array}{c}5.5 \\
\text { months }\end{array}$ & $\begin{array}{c}14 \\
\text { months }\end{array}$ & $\begin{array}{c}21-31 \\
\text { months }\end{array}$ \\
\hline
\end{tabular}

\subsubsection{Modelisation of PACE 1450}

The vertical prestressing tendon is modeled in $3 \mathrm{D}$ and the reinforcement grids and horizontal prestressing tendons are represented by membrane elements. The steel-concrete debonding is represented by a mixed interface element with the debonding law presented in section 2.2. The cracks pass straight through the structure, from the inside to the outside. Five potential cracks are integrated as 5 plans of cohesive elements into the mesh. The behavior associated with these elements is the exponential cohesive law. The creep model for the concrete is detailed in [18].

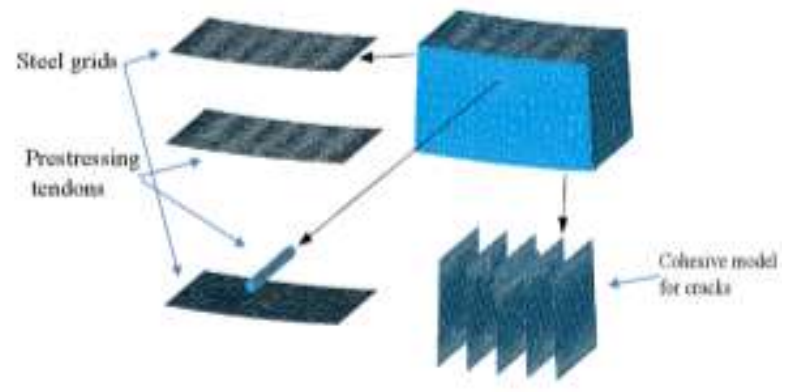

Figure 19: Mesh of PACE 1450

Table 6: Parameters of the different laws

\begin{tabular}{c|c|c|c}
\multicolumn{2}{c|}{ Concrete parameters } & \multicolumn{2}{c}{ Exponential Law } \\
\hline $\mathrm{E}$ & $26 \mathrm{GPa}$ & $\sigma_{\mathrm{t}}$ & $3 \mathrm{MPa}$ \\
\hline$v$ & 0.22 & $\mathrm{G}_{\mathrm{f}}$ & $100 \mathrm{~N} / \mathrm{m}$ \\
\hline \multicolumn{2}{c|}{ Steel parameters } & \multicolumn{2}{|c}{ Debonding Law } \\
\hline $\mathrm{E}$ & $200 \mathrm{GPa}$ & $(\alpha, \beta)$ & $(0.5,1)$ \\
\hline$v$ & 0.3 & $\tau_{\mathrm{m}}$ & $10 \mathrm{MPa}$ \\
\hline & & $\mathrm{a}_{\mathrm{m}}$ & $1 \mathrm{~mm}$
\end{tabular}

The prestressing values are given in Table 5 . Figure 20 represents the loading applied during RUN 6. The loading applied during RUN 4 and the RUN 6 are similar. The successive steps of pressure are: 4 bar, 5 bar, 5.5 and 6 bar. The opening of one crack, C15, is also shown in Figure 20. 


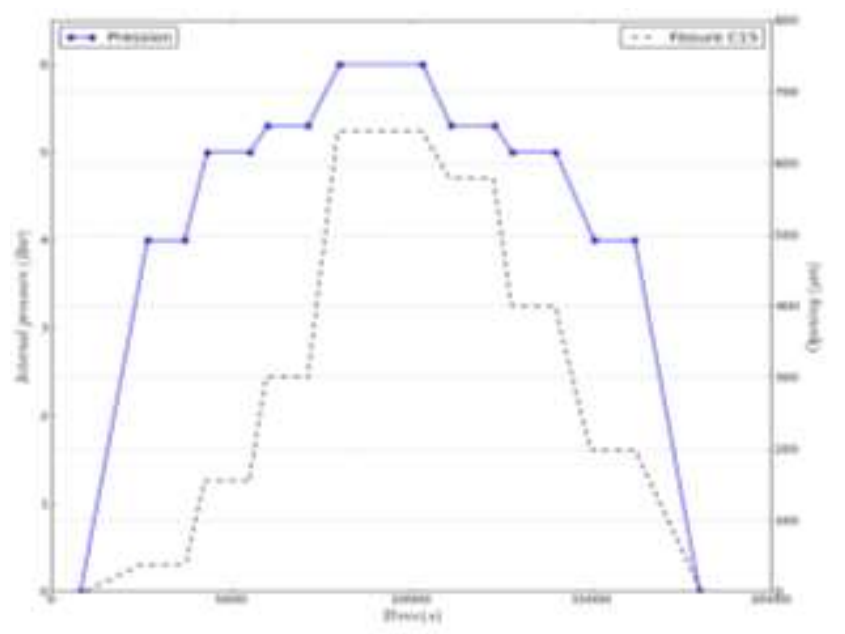

Figure 20 : Pressure scenario during RUN 6 with measured crack opening $C 15$

The simulation of the PACE1450 test is realized from the concreting of the specimen up to the date of RUN6, 31 months later. All variations of prestressing and all mechanical tests (RUN1-6) are taken into account.

The initiation of cracks during the RUN4 test is simulated. Two cracks are predicted on the $4^{\text {th }}$ and $5^{\text {th }}$ cohesive plan and the cracks opening are as expected. The opening of these two cracks during the test RUN6 is compared to experimental data from two cracks in Figure 21. The cracks $\mathrm{C} 15$ and $\mathrm{C} 11$ are observed in the experimental test. Their openings are similar to the opening of the 4th and $5^{\text {th }}$ cohesive element plan. The opening between the experimental and numerical results are consistent but not identical.

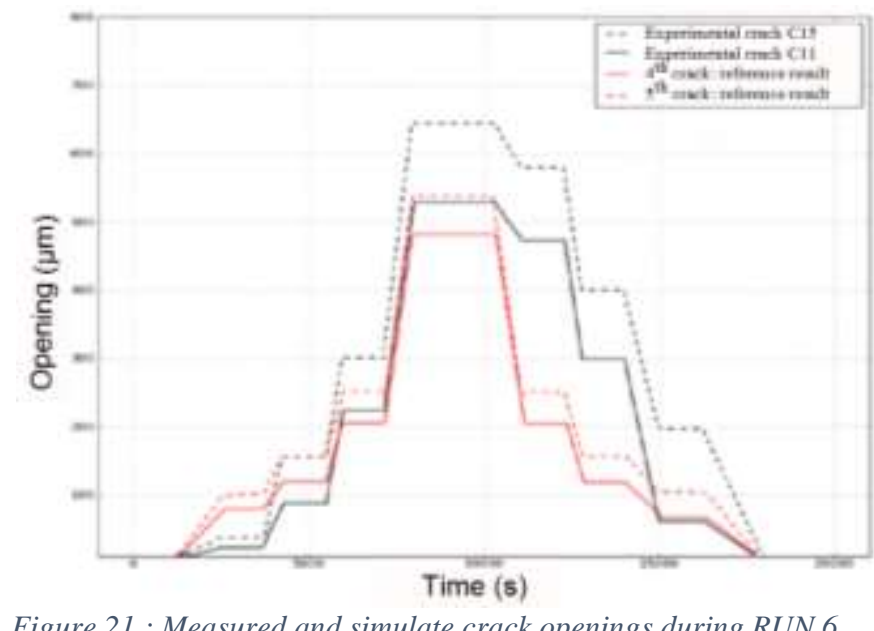

Figure 21 : Measured and simulate crack openings during RUN 6

The combination of the mixed interface finite element for the crack and the steel-concrete debonding and the creep model can simulate the behavior of a prestressed concrete structure, the crack openings during the RUN4 and the reopening during the RUN6. However the abrupt opening of the plans of cohesive elementand the sensitivity of the results with respect to the boundary conditions make it difficult the simulation of the crack during the RUN4.

\section{Simulation of a part of the containment building with an initial pre-crack state}

So far, it was shown that tools for simulating the cracking of concrete structures are available. Nevertheless, in some cases, it could be difficult to obtain the crack pattern observed on a structure by a simulation, especially for industrial structures. This difficulty could come from the misunderstanding of the loads applied on the structure, the influence of the material heterogeneities or the convergence difficulties. In this case, it seems interesting to be able to define an initial pre-cracked state for a concrete structure and to study only the evolution of the crack and not the occurrence of this cracks.

Thus, a definition of an initial cracked state is proposed and validated with the experimental test PACE1450. The advantages of the test PACE1450 are :

- Dimension and reinforcement of the steel corresponding to a confinement vessel

- Several cracks are created under a known load

- These cracks are reopened under the same load few months later and the surface openings were measured

The results from section 3.3 is considered as the reference calculation. A comparison between the reference calculation and a result which starts after the cracking of the specimen with the initial precrack state is proposed.

\subsection{Definition of the initial pre-crack state}

It is assumed here that at the date of the RUN4, cracks are present and their locations are know from observations. Then we want to predict the openings cracks 17 months later (equivalent to the RUN6).

The analysis is performed in two steps:

- A preliminary simulation is performed from concreting up to RUN4 (14 months), considering only creep and not cracking or decohesion in the structure. The mesh is thus very simple: $3 \mathrm{D}$ elements for the 
concrete and membrane elements for the steels. At the end of the RUN 4, the stress field, the displacement field and the state variables for the creep model are determined.

- For the second simulation, Two cohesive cracks are introduced in the mesh (corresponding to the $4^{\text {th }}$ and $5^{\text {th }}$ cracks of the model) and the decohesion between concrete and steel.

The initial state is defined as :

- For the concrete and the steels by projecting the stress field and the state variables of the preliminary simulation

- For the two cracks, by assuming that they are closed but fully damaged

- For the steel-concrete bond, by assuming the evolution of the slip near the vertical cracks. This evolution has been determined thanks to the observation of the results obtained in section 3.3 and figure 22 in order to obtain the following relation :

$$
\xi(x)=\xi_{\max } \frac{l-x}{l-p}
$$

With $\xi_{\max }$ being the maximum debonding of the interface, 1 the debonding length and $p$ the position of the crack.

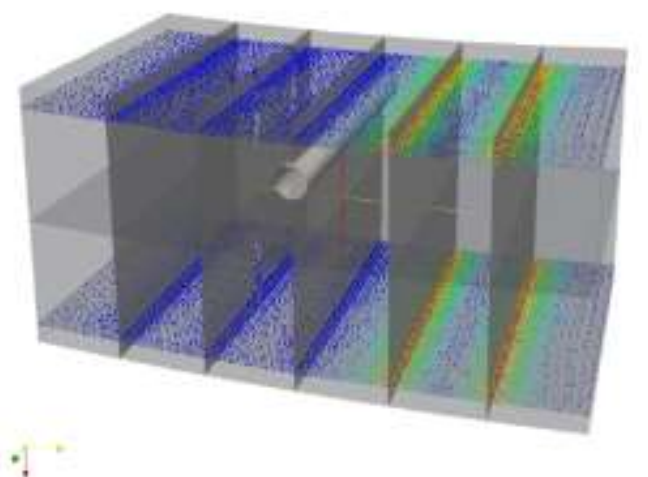

Figure 22: Visualization of the slip between steel and concrete

\subsection{Analysis of the results}

Figure 23 compares the opening of the $4^{\text {th }}$ and the $5^{\text {th }}$ cohesive element plan for the two types of analysis: the reference simulation and the calculation with an initial pre-crack state. The profiles of the two curves are very similar and the difference of the opening is at most $40 \mu \mathrm{m}$. This difference may come from the damage around the horizontal tendon that is not introduced in the initial pre-crack state.

The initial pre-crack state allows us to reproduce the opening of cracks during the RUN 6 with the following informations: position of the cracks, behaviour of concrete and an estimation of the steel-concrete debonding.

Using a simplified mesh without simulating the openings cracks until RUN 4 reduces the computing time by $30 \%$. The time duration until RUN 4 and between RUN 4 and RUN 6 are equally long (Table 5). In the case of a later appearing cracking structure, the speed-up is greater.

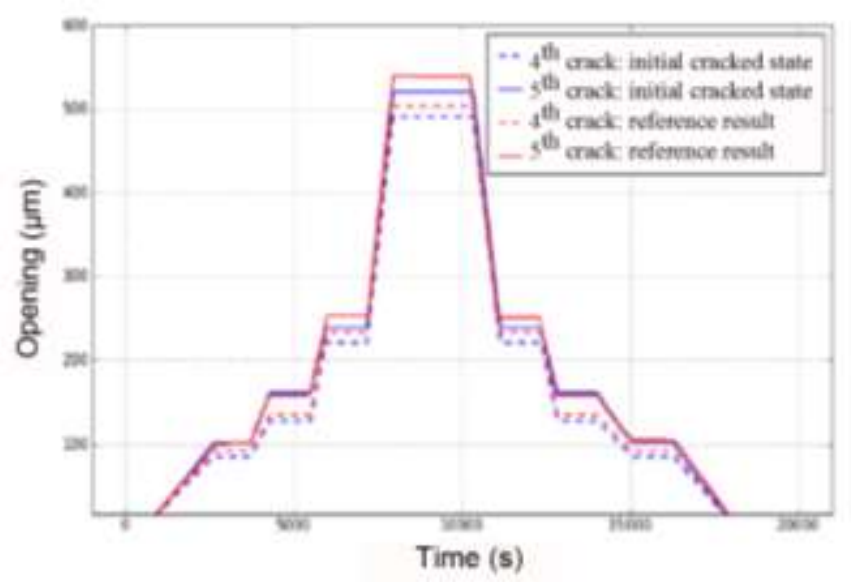

Figure 23 Evolution of the cracks openings during run 6 : Comparison between the reference calculation and method of crack insertion

\section{Conclusion}

In this article, we shown that cohesive zone models could be used to describe both the steelconcrete debonding and the cracking phenomena in reinforced concrete structures. Indeed, three structures have been simulated and compared to experimental results. Satisfactory results have been obtained both at the global and local scales, if the number of potential cracks and the discretization are sufficient.

As it is sometimes difficult to get a realistic crack pattern for industrial structures, we have proposed a methodology to define initial the precrack state of the structure. It should allow to study the evolution of the crack without simulating its occurrence. The applicability has been demonstrated on the PACE1450 experiment. Other examples are in progress, and in particular the study of other local zones of the containment vessels, that could be cracked specially during the early age due to shrinkage phenomena. 


\section{REFERENCES}

[1] Owen, D. and Hinton, 1980. Finite elements in plasticity: Theory and practice. Pineridge Press Lt

[2] Laborderie, C. 1991. Phénomènes unilatéraux dans un matériau endommageable: modélisation et application à l'analyse des structures en béton. PhD Thesis

[3] Lorentz, E. 2004.Localization phenomena and regularization methods. Local Approach to Fracture. Paris, Les Presses de l'Ecole des Mines

[4] Jendele, L. and Červenka, J. 2009. On the solution of multi-point constraints Application to FE analysis of reinforced concrete structures. Computers \& Structures, Volume 87, Issues 15-16, August.

[5] David M., 2012, Approche multi-échelle du comportement mécanique des structures en béton armé - Application aux enceintes de confinement des centrales nucléaires, Phd Thesis. Laboratoire Mécanique des Solides de Polytechnique

[6] Sanahuja, J., Dormieux, L. and Chanvillard G. 2007. Modelling elasticity of a hydrating cement paste. Cement and Concrete Research, 37(10), 1427-1439,

[7] Mazars, J. 1986. A description of micro and macroscale damage of concrete structure. Engineering Fracture Mechanics, Vol25, p729-737.

[8] Lorentz, E. and Andrieux S. 1999. A variational formulation for nonlocal damage models. International Journal of Plasticity 15(2), 119138

[9] Lorentz, E. 2008. A mixed interface finite element for cohesive zone models. Computer Methods in Applied Mechanics and Engineering 198.2

[10] Francfort G.A., Marigo J.-J., Revisiting brittle fracture as an energy minimization problem, Journal of the Mechanics and Physics of Solids, Volume 46

[11] Petersson, P.E. 1980, Fracture energy of concrete: Practical performance and experimental results, Cement and Concrete Research, Volume 10

[12] Cazes F. 2010. Construction et implementation de lois cohésives extrinsèques, PhD Thesis

[13] Needelman, A. 1987. A continuum model for void nucleation by inclusion debonding.
Journal of Applied Mechanics. 54(3)

[14] Alfano, G. 2006 On the influence of the shape of the interface law on the application of cohesive zone models. Journal Composite Sciences and Technology. Volume 66, Issue 6

[15] Goto Y. 1971. Cracks Formed in Concrete Around Deformed Tension Bars, Journal Proceedings. Volume 68-4

[16] Eligehausen, R., Popov, E. and Bertero, V. 1983. Local bond stress-slip relationships of deformed bars under generalized excitations, Technical Report UCB/EERC-83/23 of the National Science Foundation, University of California, Berkeley

[17] Ghantous, R.M., Millard A., Poyet S., François R., L'Hostis V. and Tran N.C, 2016, Experimental and numerical characterisation of load-induced damage in reinforced concrete members. Proceedings of the international conference: 9th FramCos, Berkeley, USA

[18] Ghavamian, S. 2003. Modèles de fissuration de béton, projet MECA. Revue française de génie civil volume $7-\mathrm{n}^{\circ} 5 /$

[19] Herrmann, N., Müller, H. S., Niklasch C., Michel-Ponnelle S., Le Pape Y., Bento C., 2012, PACE-1450 The crack and leakage behavior of a prestressed concrete wall considering the prestressing loss due to aging

[20] Lorentz, E., 2005, Ill-posed boundary conditions encountered in 3D and plate finite element simulations, Finite Elements in Analysis and Design 41 